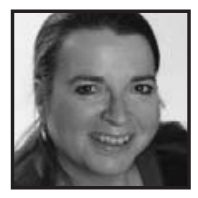

\title{
UNESCO World Conference on Arts Education: A Poetic Review
}

\author{
Monica Prendergast, Lesley University
}

\section{INTRODUCTION}

In March of 2006 I was invited to present a paper on my dissertation research at the first world gathering on arts education sponsored by the United Nations Education, Scientific and Cultural Organization [UNESCO] in Lisbon, Portugal. The conference was attended by delegates from over 100 nations and was intended to encourage countries that offer little or no arts education to see the value of the arts in schools, and to change their policies and practices.

What follows are my poetic impressions and representations of that experience. Two poems contained in this suite-for Amanda Lichtenstein (a mostly-found poem) and for Eric Booth (a mostly-found poem)_fall into the long literary tradition of found poetry; that is, they are crafted from preexisting source texts, in this case my notes taken as I listened to these two speakers at the UNESCO conference (see also Butler-Kisber, 2002; Prendergast, 2004, 2006; Sullivan, 2000).

\section{day one - preaching to the converted}

\footnotetext{
lie

inside a huge marble jewel-box theatre inside a huger cultural riverside complex in Lisbon
} 
(day one)

and i hide

inside this private box seat

behind a closed door

from twenty expert speakers

(17 men \& 3 women)

banging their own drums

(some soft / some loud)

about art and education

in the twenty-first century world

speaking empathy

imagination

creativity

showing self-centredness

power-pointedness

political correctness

i am

jet-lagged
alienated (so few women)
$\&$ bored

so

i curl up with my head

on a jacket-made pillow

\& dream

of a global conference

on arts education

that

looks

somewhat other than this 
that

lives

somewhere other than here

\section{to become an artist}

you must give

a part of

your life

(it is not enough)

to take a course

spend 5 or even 50

minutes a day

you must rather

take apart

the classroom

dread-embedded in

the prison discipline

of school

(it is not enough)

you must create

a critical pedagogy

transmitted

\& transformed

through the arts

as omnipresent

as necessary

as air

(to do otherwise

it is not enough) 


\section{day two - hyphens}

today i forgo

listening

for seeing

go

to 3 galleries

on my feet

(\& my toes)

for hours

share these marvel-

filled yet

almost-

empty spaces

with school-

children

watch them

meet Rembrandt

Bosch

Degas

Manet

for the $1^{\text {st }}$ time

huddle in close-

quarter groups

before a master-

piece (meal

for the soul)

almost shout

their answers

as if

enthusiasm alone

might wake 
these long-

dead faces

might enter

these long-

gone land-

scapes

caught in suspended beauty

and immortal surprise

taking us some-

where other

somewhere

these children

(\&i)

so very need

to go

\section{day three - questions}

art for art's sake

or

for the sake of others?

advocacy burnout

burns brightly

here

why must we always

fight for

what we do?

inside the curriculum

is safer

(more conservative?) 
outside the curriculum

is braver

(tilting at quixotic

windmills?)

complacent

or

resistant?

on the margins

or

at the centre?

art may

consume

through

creation

(like fire)

how can

this truth

hard as

coal or

diamond

ever be

taught?

\section{for Amanda Lichtenstein (a mostly-found poem) ${ }^{1}$}

smashed up

in these moments

lie poetic under-

pinnings

of our work

umbilical awareness 
each

$$
\text { bound up }
$$

in the other

autobiographical revolutions

ultimate gestures

$$
\text { of inquiry }
$$

resisting the corporatization

$$
\text { of the mind }
$$

i walk

inside myself

$$
\text { to be }
$$

comforted

by art

$$
\text { day four — closing session }
$$

all education

is an art

(the art

$$
\text { of discovery) }
$$

a space

$$
\text { for peace }
$$

joy

pleasure

a place

for change 


\section{for Eric Booth (a mostly-found poem) ${ }^{2}$}

art is:

the power

to transform

the most

degrading

of settings

to say "wow"

in poignancy

in bravado

tsunamis of

wordsthoughtsideas

wash over

we frail vessels

engaged in complexity

remember:

tolerate paradox

experience the body

embrace chaos

be

the strange attractor

who cannot measure

a lightening

of the heart

or

a decrease

in boredom

remember: art is

oxygen
\[ \begin{array}{l}\text { \& anti- } \\ \text { biotic }\end{array} \]




\section{Notes}

1. Lichtenstein is a teaching artist in Chicago and a published poet. This poem was created from notes taken at her presentation.

2. Booth is an American arts educator and advocate who has worked for the Kennedy and Lincoln Centers, teaches at Juilliard and was founding editor of Teaching Artist Journal.This poem is created from notes taken at his closing address.

\section{References}

Butler-Kisber, L. (2002). Artful portrayals in qualitative inquiry: The road to found poetry and beyond. The Alberta Journal of Educational Research, XLVIII(3), 229-239.

Prendergast, M. (2004). 'Shaped like a question mark': Found poems from Herbert Blau's The Audience. Research in Drama Education, 9(1), 73-92.
Prendergast, M. (2006). Found poetry as literature review: Research poems on audience and performance. Qualitative Inquiry, 12(2), 369-388.

Sullivan, A. (2000). The necessity of art: Three found poems from John Dewey's Art as experience. International Journal of Qualitative Studies in Education. 13(3), 325-327.

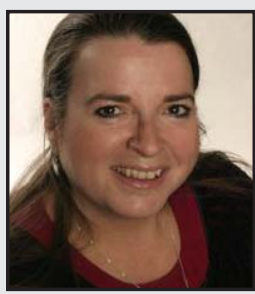

Monica Prendergast's work has been published in a number of education journals (Youth Theatre Journal, Alberta Journal of Educational Research, Journal of Aesthetic Education). Her research poetry has been published in the International Journal of Education and the Arts, Research in Drama Education, Language and Literacy and Qualitative Inquiry. Monica's books include Teaching Spectatorship: Essays and Poems on Audience in Performance (Cambria Press, 2008) and a coedited collection, Poetic Inquiry: Vibrant Voices in the Social Sciences (in press). She is a faculty member in the Graduate School of Arts and Social Sciences, Division of Creative Arts in Learning, at Lesley University in Cambridge, Massachusetts. 